\title{
Curative effect of the recent photofrin photodynamic adjuvant treatment on young patients with advanced colorectal cancer
}

\author{
BO SUN ${ }^{1}$, WEI LI ${ }^{1}$ and NING LIU ${ }^{2}$ \\ Departments of ${ }^{1}$ General Surgery and ${ }^{2}$ Emergency Surgery, The First People's Hospital of Xuzhou, \\ Xuzhou, Jiangsu 221002, P.R. China
}

Received November 20, 2015; Accepted February 2, 2016

DOI: $10.3892 / \mathrm{ol} .2016 .4179$

\begin{abstract}
Advanced colorectal cancer has a high mortality rate and conventional treatments have poor therapeutic effects. The aim of the present study was to analyze the recent curative effect and adverse reaction of photofrin photodynamic adjuvant treatment on young patients with advanced colorectal cancer. A total of 23 patients with advanced colorectal cancer who had accepted semiconductor laser photodynamic adjuvant treatment were selected as the observation group. In addition, 30 patients who had accepted concurrent radiotherapy and chemotherapy during the same period served as the control group. The observation group received photofrin $(2 \mathrm{mg} / \mathrm{kg})$ intravenously in $100 \mathrm{ml}$ of $5 \%$ glucose, followed by the introduction of the endoscopic optical fiber to deliver laser radiation with an intensity of $630 \mathrm{~nm}$ wavelength pulse power. After 2 days, necrotic tissues were removed and irradiation of the original or new tumor lesions was performed and necrotic tissues were removed. The total effective rate and survival time was higher and the length of hospital stay was shorter in the observation group in comparison with the control group. The differences were statistically significant $(\mathrm{P}<0.05)$. The number of patients in the control and observation groups with symptoms of hematochezia, change in bowel habit, intestinal stimulation and incomplete intestinal obstruction were reduced. Additionally, the reduced ratio of the observation group was significantly increased in comparison with the control group $(\mathrm{P}<0.05)$. The adverse reaction rate of the observation group was lower than that of the control group and this difference was also statistically significant $(\mathrm{P}<0.05)$. In conclusion, use of photodynamic treatment for young patients with advanced colorectal cancer can effectively improve the clinical symptoms and reduce complications.
\end{abstract}

Correspondence to: Dr Ning Liu, Department of Emergency Surgery, The First People's Hospital of Xuzhou, 19 North Zhongshan Road, Xuzhou, Jiangsu 221002, P.R. China

E-mail:1mk877@163.com

Key words: photofrin, advanced colorectal cancer, photodynamic treatment, hematochezia, intestinal obstruction

\section{Introduction}

The incidence and mortality rates of advanced colorectal cancer have been on the increase in recent years. Data presented at the 8th Shanghai International Settlement rectal cancer forum in 2012 demonstrated that the incidence of colorectal cancer is the highest in western developed countries with regard to malignancies and ranks fourth in China. The mortality rate ranks second in developed countries and sixth in China (1). The pathogenesis of the disease is associated with genetic and long-term chronic intestinal inflammation (2). Early clinical symptoms are atypical and $40-50 \%$ patients have been diagnosed with metastasis due to a lack of specific screening tools (3). The degree of malignancy is higher especially for young patients (4). Conventional treatments such as surgical resection, radiotherapy and chemotherapy have poor therapeutic effects and considerable side effects (5). Microwave and high power laser treatments can increase severe complications including intestinal bleeding, esophageal mediastinal fistula or esophagotracheal fistula $(6,7)$. As a means of local tumor ablation, photodynamic therapy (PDT) has been developing rapidly in recent years. PDT has a slight effect on normal tissues, but can kill tumor cells selectively and repeated treatment improves the therapeutic effect (8). PDT is beneficial in the treatment of colorectal cancer, it does not cause cicatricial stenosis. In addition, it can significantly improve the quality of life of patients with cancer and extend their life span $(9,10)$. PDT has been widely applied in the treatment of throat, bladder, lung, esophageal, and gastric cancer (11).

In the present study, semiconductor laser PDT was used to treat 23 young patients with advanced colorectal cancer and its importance for the clinical treatment of advanced colorectal cancer was assessed.

\section{Patients and methods}

Patients and control. Twenty-three patients with advanced colorectal cancer who had accepted semiconductor laser PDT were chosen between September, 2010 and February, 2014 in The First People's Hospital of Xuzhou as the observation group. The patients did not undergo surgery, could not be relieved of the complete or incomplete obstruction and experienced relapse after accepting radiotherapy, chemotherapy and surgical resection. Of the 23 patients, 16 were men and 
Table I. Clinical efficacy of the treatment.

\begin{tabular}{lcccccccc}
\hline Groups & Patients & CR & PR & MR & NR & Total effective rate & Survival time (months) & Length of hospital stay \\
\hline Control & 30 & 2 & 5 & 5 & 18 & 40 & $3.01 \pm 1.12$ & $19.72 \pm 5.21$ \\
Observation & 23 & 2 & 6 & 8 & 7 & 69.57 & $6.23 \pm 1.65$ & $13.47 \pm 4.46$ \\
t & & & & & & 2.341 & 3.846 & 2.212 \\
P-value & & & & & & 0.035 & 0.013 & 0.036 \\
\hline
\end{tabular}

CR, complete response; PR, partial response; MR, mild response; NR, no response.

Table II. PDT treatment relieved the clinical symptoms.

\begin{tabular}{|c|c|c|c|c|c|c|c|}
\hline \multirow[b]{2}{*}{ Groups } & \multirow[b]{2}{*}{ Patients } & \multicolumn{3}{|c|}{ Before treatment } & \multicolumn{3}{|c|}{ After treatment } \\
\hline & & Hematochezia & $\begin{array}{c}\text { Bowel habits } \\
\text { and intestinal } \\
\text { stimulation }\end{array}$ & $\begin{array}{l}\text { Incomplete } \\
\text { intestinal } \\
\text { obstruction }\end{array}$ & Hematochezia & $\begin{array}{l}\text { Bowel habits } \\
\text { and intestinal } \\
\text { stimulation }\end{array}$ & $\begin{array}{c}\text { Incomplete } \\
\text { intestinal } \\
\text { obstruction }\end{array}$ \\
\hline Control & 30 & 9 & 17 & 4 & 7 & 12 & 3 \\
\hline Observation & 23 & 6 & 13 & 4 & 3 & 7 & 2 \\
\hline
\end{tabular}

PDT, photodynamic therapy.

Table III. Adverse reaction rate reduced in PDT treatment.

\begin{tabular}{lccccc}
\hline Groups & Patients & $\begin{array}{c}\text { Intestinal, } \\
\text { rectovesical fistula or } \\
\text { rectovaginal fistula }\end{array}$ & $\begin{array}{c}\text { Photosensitive } \\
\text { dermatitis }\end{array}$ & $\begin{array}{c}\text { Lower } \\
\text { gastrointestinal } \\
\text { hemorrhage }\end{array}$ & $\begin{array}{c}\text { Myelosupression, } \\
\text { liver and kidney } \\
\text { toxicity }\end{array}$ \\
\hline Control & 30 & 5 & 3 & 4 & 2 \\
Observation & 23 & 2 & 1 & 3 & 0 \\
\hline
\end{tabular}

PDT, photodynamic therapy.

7 were women, with an age range of 23-58 years with a median age of 41.9 years. Of the 23 patients, 21 had rectal cancer and 2 had sigmoid carcinoma. Advanced colorectal cancer in the 23 patients was confirmed pathologically, 10 patients were in Dukes $\mathrm{C}$ stage and 13 patients were in D stage. Seven patients had liver metastasis and 16 patients were out of control after accepting to undergo chemotherapy. Four patients had tumor recurrence after surgical resection and three patients had tumor recurrence after radiotherapy. Hematochezia was observed in 6 patients, a change in bowel habit and intestinal stimulation was observed in 13 patients, and 4 patients exhibited incomplete intestinal obstruction. Thirty patients who accepted concurrent radiotherapy and chemotherapy served as the controls. Of the 30 patients, 21 were men and 9 were women, with an age range of 27-56 years, and a median age of 41.9 years.

The study was approved by the ethics committee of The First People's Hospital of Xuzhou. Written informed consent was provided by the patients.

PDT. Laser therapy was performed using Diomed 630 (British Laser Instrument Co., Ltd., Diomed, Cambridge, UK) with an output of $630 \mathrm{~nm}$ wavelength pulse power. The optical fibers included were column-shaped and flat cut fibers. The length of the terminal of the column-shaped fiber was $2-5 \mathrm{~cm}$ and the photosensitizer was photofrin (Canadian Pharmaceutical Co., Ltd., Québec, Canada).

Photofrin at a final concentration of $2 \mathrm{mg} / \mathrm{kg}$ was administered to the patients intravenously in $100 \mathrm{ml}$ of $5 \%$ glucose. After $48 \mathrm{~h}$, laser irradiation at $630 \mathrm{~nm}$ was delivered through a flat cut optical fiber. For different lesion ranges, different lengths of column-shaped fibers were used. The irradiation dose of different types set in the machine was in accordance with differences of the tumor length in the cavity. Normally, 1-3 segments were irradiated each time and the irradiating time was $\sim 12 \mathrm{~min}$, with an energy density of $200 \mathrm{~J} / \mathrm{cm}^{2}$. Each segment was interlinked when treated, at least exceeding $0.5 \mathrm{~cm}$ of the tumor boundary, leading to the illumination range completely covering the tumor area. The necrotic tissues were removed endoscopically after 2 days and repeated irradiations were performed at the original tumor and new tumor sites to improve the therapeutic effect. The patients underwent enteroscopic examination after one month to monitor the therapeutic 
effect of the treatment. It was identified that 5 patients used intestinal stent after laser radiation.

Curative effect. The general standards to classify colon cancer in the present study were: i) complete response (CR), where the tumor completely disappeared, tissue histopathology was negative and this condition lasted $\geq 1$ month; ii) partial response (PR), where tumor maximum diameter and vertical diameter or the tumor height narrowed $>50 \%$ and this condition lasted $\geq 1$ month; iii) mild response, where the tumor narrowed $<50 \%$ and this condition lasted $\geq 1$ month; iv) no response, no change or enlargement of the tumor.

Statistical analysis. The SPSS 17.0 software (SPSS, Inc., Chicago, IL, USA) was used to analyze the results. Data were presented as mean \pm standard deviation. Comparisons between groups was performed by t-test and Chi-square test. $\mathrm{P}<0.05$ was considered to indicate a statistically significant difference.

\section{Results}

Clinical efficacy of the PDT treatment. The patient age, gender and stages of cancer were not significantly different between patients in the observation and control groups $(\mathrm{P}>0.05)$. The total effective rate of the observation group was significantly higher when compared with that of the control group. An increased survival time and decreased length of hospital stay was also identified in patients of the observation group in comparison with those of the control group (Table I).

Clinical symptoms relieved in patients who had received PDT. The number of patients exhibiting symptoms including hematochezia, change in bowel habits, intestinal stimulation and incomplete intestinal obstruction were distributed similarly prior to treatment in the two groups. However, following PDT treatment, the number of patients exhibiting these symptoms became reduced in the observation group. Conventional treatments such as radiotherapy and chemotherapy did not reduce the number of patients with these symptoms, as is evident in the control group. Additionally, the reduced ratio in the observation group was significantly higher than that of the control group $\left(\chi^{2}=2.094, \mathrm{P}=0.041\right.$; Table II $)$.

Adverse reaction rate reduced in PDT treatment. The adverse reaction rate in the observation group was significantly reduced compared to that of the control group $\left(\chi^{2}=2.997\right.$, $\mathrm{P}=0.031$; Table III).

\section{Discussion}

PDT comprises a photosensitizer, laser and dioxygen, and each substance is harmless to cells (12). The rapid development of the photosensitizer and laser irradiation systems has led to PDT gradually becoming a new method used in the treatment of various types of tumor (13). The biological mechanism of PDT has been fully understood. The basic principle is the photochemistry principle of the photodynamic laser, which utilizes a laser of specific wavelength to activate the photosensitizer remaining in the tumor tissues. Thus, the photosensitizer operates with oxygen in tumor tissues, producing robust radicals from singlet oxygen. Consequently, colon cancer cells are attacked by oxidation, subsequently killing tumor cells $(14,15)$.

PDT has gradually become an anticancer strategy employed in the treament of colorectal cancer (16). Compared with traditional anticancer strategies such as surgery, radiotherapy and chemotherapy, PDT has numerous inherent advantages including accurately positioning target tumor tissues, relatively non-invasive treatment, non-requirement of repeated drug administration, relative ease of operation, fewer side-effects, little trauma, low toxicity, wide range of applications, protecting appearance and important organ functions, less irradiation to the blind region, relatively steady curative effect, selective damage to tumor tissues and suitability for colon cancer patients of all ages and stages (17-19).

Previous studies focusing on progressive stage colon cancer have demonstrated that the PR rate of patients is $44 \%$ and the CR rate is $35 \%(20,21)$. The total effective rate of PDT for patients with advanced colon cancer to control bleeding, relieve pain and intestinal obstruction reached $70 \%(22,23)$. In this study, the total effective rate of the observation group was significantly higher than that of the control group. The former's survival time was also significantly higher and the length of hospital stay was significantly reduced. Furthermore, it was identified that the symptoms of patients in the observation group with hematochezia, change in bowel habits, intestinal stimulation and incomplete intestinal obstruction were alleviated and the adverse reaction rate was markedly decreased. A minor adverse reaction was primatily skin photosensitivity following laser irradiation. The curative effect of the photosensitizer with laser irradiation treatment was therefore more beneficial than conventional treatments. Thus, photofrin photodynamic treatment on young patients with advanced colorectal cancer can be used as an adjuvant treatment option and has relatively great clinical value for promotion.

\section{References}

1. Jemal A, Siegel R, Xu J and Ward E: Cancer statistics. CA Cancer J Clin 6: 277-300, 2010.

2. De Mattos-Arruda L, Dienstmann R and Tabemero J: Development of molecular biomarkers in individualized treatment of coloreetal cancer. Clin Colorectal Cancer 10: 279-289, 2011.

3. Li M, Li JY, Zhao AL and Gu J: Do young patients with colorectal cancer have a poorer prognosis than old patients. J Surg Res 167: 231-236, 2011.

4. Siegel RL, Jemal A and Ward EM: Increase in incidence of colorectal cancer among young men and women in the United States. Cancer Epidemiol Biomarkers Prev 18: 1695-1698, 2009.

5. Yasui M, Ikeda M, Miyake M, Ide Y, Okuyama M, Shingai T, Kitani K, Ikenaga M, Hasegawa J, Akamatsu H, Murata K, Takemasa I, Mizushima T, Yamamoto H, Sekimoto M, Nezu R, Doki Y and Mori M: Comparison of bleeding risks related to venous thromboembolism prophylaxis in laparoscopic vs open colorectal cancer surgery: a multicenter study in Japanese patients. Am J Surg: December 13, 2015 (Epub ahead of print). doi: 10.1016/j.amjsurg.2015.

6. Yu M, Guo F, Wang J, Tan F and Li N: Photosensitizer-Loaded pH-Responsive Hollow Gold Nanospheres for Single LightInduced Photothermal/Photodynamic Therapy. ACS Appl Mater Interfaces 7: 17592-17597, 2015.

7. Triesscheijn M, Baas P, Schellens JH and Stewart FA: Photodynamic therapy in oncology. Oncologist 11: 1034-1044, 2006.

8. Gollnick SO, Owczarczak B and Maier P: Photodynamic therapy and anti-tumor immunity. Lasers Surg Med 38: 509-515, 2006.

9. Akimoto J: I. Photodynamic therapy for glioblastoma. Gan To Kagaku Ryoho 42: 678-682, 2015 (In Japanese). 
10. Asnaashari M, Mojahedi SM, Asadi Z, Azari-Marhabi S and Maleki A: A Comparison of the antibacterial activity of the two methods of photodynamic therapy (using diode laser $810 \mathrm{~nm}$ and LED lamp $630 \mathrm{~nm}$ ) against Enterococcus fecalis in extracted human anterior teeth. Photodiagn Photodyn Ther 12: 24-26, 2015.

11. Rajendran M: Quinones as photosensitiser for photodynamic therapy: ROS generation, mechanism and detection methods. Photodiagnosis Photodyn Ther 13: 147-149, 2015.

12. Fanjul-Velez F, Salas-Garcia I, Torre-Celeizabal C, Zverev M and Arce-Diego JL: Analysis of low intensity laser therapy as adjuvant to photodynamic therapy in non-melanoma skin cancer. Conf Proc IEEE Eng Med Biol Soc 2015: 6900-6903, 2015.

13. Basoglu H, Bilgin MD and Demir MM: Protoporphyrin IXloaded magnetoliposomes as a potential drug delivery system forphotodynamic therapy: fabrication, characterization and in vitro study. Photodiagnosis Photodyn Ther: Jan 2, 2016 (Epub ahead of print). doi: 10.1016/j.pdpdt.2015.12.010.

14. Kawczyk-Krupka A, Bugaj AM, Latos W, Zaremba K, Wawrzyniec K, Kucharzewski M and Sieroń A: Photodynamic therapy in colorectal cancer treatment - the state of the art in preclinical research. Photodiagnosis Photodyn Ther 12: 32-34, 2015.

15. Schumann C, Taratula O, Khalimonchuk O, Palmer AL, Cronk LM, Jones CV, Escalante CA and Taratula O: ROS-induced nanotherapeutic approach for ovarian cancer treatment based on the combinatorial effect of photodynamic therapy and DJ-1 gene suppression. Nanomedicine 11: 1961-1970, 2015.
16. Maeda H, Tsukigawa K and Fang J: A Retrospective 30 Years After Discovery of the EPR Effect of Solid Tumors: Next-Generation Chemotherapeutics and Photodynamic-therapy-Problems, Solutions, Prospects. Microcirculation: Aug 3, 2015 (Epub ahead of print).

17. Youssef AA and Reygagne P: Successful treatment of extramammary Paget's disease of the scalp with photodynamic therapy. Int J Dermatol 145: 14-15, 2015.

18. Kumta NA, DeRoche K and Kahaleh M: Temoporfin photodynamic therapy in advanced hilar ductal carcinoma: A promising endoscopic modality. Hepatology 62: 1342-1343, 2015.

19. Jurič IB, Plečko V, Anić I, Pleško S, Jakovljević S, Rocca JP and Medioni E: Antimicrobial efficacy of photodynamic therapy, $\mathrm{Nd}$ :YAG laser and QMiX solution against Enterococcus faecalis biofilm. Photodiagnosis Photodyn Ther 14: 18-20, 2015.

20. Pansa MF, Lamberti MJ, Cogno IS, Correa SG, Rumie Vittar NB and Rivarola VA: Contribution of resident and recruited macrophages to the photodynamic intervention of colorectal tumor microenvironment. Tumour Biol 12: 32-34, 2015.

21. Fluehler C, Colli C, Gatti A and Trevisan G: Photodynamic therapy for nonmelanoma skin cancer of the genital area: our experience. Acta Dermatovenerol Croat 23: 148-149, 2015.

22. Ocakoglu K, Er O, Kiyak G, Lambrecht FY, Gunduz C and Kayabasi C: (131)I-Zn-Chlorophyll derivative photosensitizer for tumor imaging and photodynamic therapy. Int J Pharm 493: 96-101, 2015.

23. Dąbrowski JM and Arnaut LG: Photodynamic therapy (PDT) of cancer: from local to systemic treatment. Photochem Photobiol Sci 14: 1765-1780, 2015. 